Revista do CESP, Belo Horizonte, v.36, n.56, p. 63-77, 2016

\title{
Os desastres de uma escritura em chamas
}

\section{The disasters of a writing on fire}

Cid Ottoni Bylaardt

Professor Associado II da Universidade Federal do Ceará

Bolsista de Produtividade N2 do CNPq

cidobyl@pq.cnpq.br

Resumo: Caminho como uma casa em chamas, de António Lobo Antunes, é um romance construído como um prédio de apartamentos, de onde emanam as narrativas que se sucedem no livro. Apesar da aparente organização formal, Antunes nos oferece um texto que se esquiva das noções tradicionais de trama romanesca. Os textos são independentes, ainda que dialoguem entre si pela proximidade dos enunciadores, e não se estruturam pela lógica conflito-clímax-desenlace. Este texto pretende mostrar como a narrativa contemporânea compõe suas tramas escriturais, sua escritura em chamas, que se faz de seus desastres, suas ruínas, suas perdas, numa ação negativa de eterna falta, de busca sem fim, de insuficiência da linguagem, de instabilidade do signo. O que chamamos experiência real, assim, é estruturada no romance com fraturas, envolta em chamas, e é aí, na paixão da arte, que a literatura impõe a indecidibilidade entre a ficção e a outra coisa que chamamos mundo. $\mathrm{O}$ suporte teórico deste ensaio inclui considerações de Maurice Blanchot, Giorgio Agamben, Jacques Derrida, Didi-Huberman, Emmanuel Levinas e Lélia Parreira Duarte.

Palavras-chave: Literatura contemporânea; Lobo Antunes; escritura em chamas. 
Abstract: Caminho como uma casa em chamas [I walk like a house on fire], de António Lobo Antunes, is a novel composed as a building of apartments, from where come the voices that narrate the stories in the book. Despite the apparent formal organization, Antunes presents us a text that doesn't follow the traditional notions of plot. The texts are independent, although they talk among each other considering the proximity of the enunciators, and they don't follow the logic conflict-climax-denouement. This text intends to show how contemporary narrative builds its plots, its flaming writing, made of its disasters, its ruins, its losses, in a negative action of eternal fault, of neverending search, of language insufficiency, of sign's instability. What we call real experience, thus, is structured in the novel with fractures, in flames, and it's just there, in the passion of art, that literature imposes its undecidedness between fiction and the other thing that we call world. The theoretical sponsor of this essay includes considerations of Maurice Blanchot, Giorgio Agamben, Jacques Derrida, Didi-Huberman, Emmanuel Levinas and Lélia Parreira Duarte.

Keywords: Contemporary literature; Lobo Antunes; writing on fire.

Recebido em 6 de dezembro de 2016 Aprovado em 6 de abril de 2017

Qui se dérobera au feu qui ne se couche pas? ${ }^{1}$ (Heráclito, citado por BLANCHOT, 2003, p.7)

Relendo um texto de Lélia Duarte, de quem se poderia justamente homenagear a sensibilidade e a acuidade de leitura e escrita, sobre o livro de contos de Maria Judite de Carvalho, Seta despedida, deparo-me com o seguinte trecho:

Perséfone parece portanto presente nesses contos, em que circulam mortos-vivos (...), para quem a vida é um desconforto, embora suas histórias possam ser vistas como uma elaboração que leva a dor para o campo da beleza. Certamente por isso essas histórias são inconclusas, repletas de oscilações e indecisões, estranhamentos e não-

\footnotetext{
${ }^{1}$ Trad. do autor: Quem se esquivará ao fogo que não se apaga?
} 
saberes, em que apenas as palavras são nítidas, em sua instabilidade, mas em que o sentido é sempre impossível de ser fixado, porque tecido com a ambiguidade presença/ ausência própria da morte. (DUARTE, 2008, p. 253-254)

Lélia Duarte poderia muito bem estar-se referindo ao romance Caminho como uma casa em chamas, de António Lobo Antunes. A única "inadequação", talvez, considerando-se uma rígida divisão de gêneros, seria a referência às narrativas como contos. Não obstante, quem lê o livro de Lobo Antunes depara-se com vinte e cinco narrativas que poderiam muito bem ser lidas como contos. Contos contemporâneos, desvinculados das noções convencionais de trama (conflito-clímax-desenlace), ainda que conflitos e tensões não faltem às narrativas. As ideias que circulam no texto de Lélia Duarte parecem encontrar uma estranha ressonância no mundo criado por Lobo Antunes em Caminho como uma casa em chamas.

Além da referência a uma casa no título, o que chama a atenção numa primeira leitura é a arquitetura do romance, que se constrói como uma casa, ou melhor, como um prédio de apartamentos de quatro andares e mais o sótão. Cada andar do edifício abriga dois apartamentos, duas moradas. Os títulos dos “capítulos" constituem referências às localizações das moradas: SEGUNDO DIREITO, SEGUNDO ESQUERDO, TERCEIRO ESQUERDO, PRIMEIRO ESQUERDO, RÉS DO CHÃO DIREITO, RÉS DO CHÃO ESQUERDO, PRIMEIRO DIREITO, TERCEIRO DIREITO, nesta ordem. Os vinte e cinco capítulos-contos têm extensão semelhante, e obedecem a uma rigorosa ordem sequencial, ainda que esta ordem e esta sequência não exerçam absolutamente nenhuma influência no sentido das narrativas e do romance como um todo. Se se embaralhassem os capítulos e os fossem colocando um a um ao sabor da sorte, como o poema dadá da receita de Tristán Tzara, a diferença não seria grande em termos de um resultado, um dizer, uma chegada do caminho percorrido.

Mais uma vez nos reportamos à arquitetura dos romances de Lobo Antunes, a simetria, as semelhanças que escondem uma extraordinária dessemelhança, a organização que parece sugerir uma arquitetura definida que possa conduzir e conter a linguagem da ficção e que redunda em fracasso: fracasso da linguagem, fracasso da arquitetura, fracasso da escritura.

As vozes enunciadoras do romance pertencem aos moradores desses apartamentos, ou seres relacionados a eles, dando às vezes a 
impressão de que é a própria morada que fala. Aí desfilam um homem míope que se casou com uma mulher cega; uma juíza gorda e mal-amada, de 59 anos; um coronel egresso da guerra de Angola, e a mulata com quem ele viveu, Sofia Rosa; um homem bêbado que vive a ameaçar a mulher e a filha; um homem judeu e sua irmã, fugidos do nazismo; um suposto subversivo - inocente ou não - preso e torturado pela polícia; uma mulher gorda e feia que anseia por um caso com o chefe-de-seção; uma atriz idosa que vive da glória passada e sua acompanhante. Os depoimentos, ou memórias, ou narrativas referidas pelos personagens se repetem mais duas vezes, sempre na mesma ordem, e terminam com a fala de um morador do sótão, como a pousar uma espécie de cumeeira conclusiva sobre o edifício escritural.

O edifício se constrói de escritura. Os personagens, aqui e ali, declaram estar escrevendo. O bêbado, a certa altura, diz: "enquanto escrevo isto vem-me à ideia a lua que não existia e o vento que se a gente falasse dispersava os discursos" (p. 57). ${ }^{2}$ Aí, o estado alterado de consciência pelo álcool convoca o que se dispersa, o que não existe. O judeu do résdo-chão direito diz da dificuldade de escrever, da confusão que se forma na cabeça de quem escreve: "estou a misturar capítulos, a atenção escapa, a mão escapa, felizmente uma asneira que apanhei a tempo, às vezes não dou por elas mas desta feita consegui, que complicado escrever" ( $p$. 306). O subversivo do rés-do-chão esquerdo parece ter consciência de estar preso no romance, sem autonomia para criar ou mudar as coisas: "no caso de mandar eu no livro rasurava este capítulo mas não passo de uma personagem que o autor manipula como lhe dá na gana, embora no texto não se tenha essa noção os meus murmúrios espaçados e em certos instantes sem nexo" (p. 317). A filha do bêbado refere-se em certo momento a uma localidade chamada Vouzela, que havia aparecido no romance antes deste (p. 286). A acompanhante da atriz, ao tentar afastar a lembrança de um homem que teve em algum momento de sua vida, também declara sua dificuldade de articular memória e escritura: "houve um homem e ponto final, não me obriguem a escrever sobre isso, não é que doa, acho que não teve importância" (p. 337). Mais adiante, ela lamenta a ausência de poesia em sua vida e naquele prédio em chamas, o que a impede de escrever de maneira mais poética: "e agora apetecia-

\footnotetext{
${ }^{2}$ As referências ao romance Caminho como uma casa em chamas serão indicadas apenas com os números de páginas entre parênteses.
} 
me uma passagem lírica para contrastar mas não me vem nenhuma" (p. 341). Procura então dar um cunho filosófico a sua escrita: "eis uma boa ocasião para alongar-me acerca da alma humana" (p. 341).

Há momentos em que os personagens parecem comentar passagens do livro enunciadas por outrem, como na cena em que a mulher do primeiro direito se refere a um comentário do homem do primeiro esquerdo: "o bêbedo a concordar, ponham anuir que impressiona" (p. 103). Concordar, anuir, pode ser a fala do bêbado, ou da atriz, ou da mulher gorda, ou de ninguém, provavelmente a fala da própria escritura, do livro que fala porque não pode parar de falar.

O próprio autor, o que tem seu nome na capa, parece anunciar seus serviços, não de escritor, mas de bombeiro, simulacro de profissão, de tarefas: "o cartão que dizia Antunes \& Lobo Todos Os Trabalhos de Canalização Deslocamo-nos Ao Seu Domicílio A Preços Módicos” (p. 89). A referência parece dizer que por trás daquela escritura há um ser que, apesar de se julgar senhor do texto, não sabe bem para onde ele vai, assim como seus personagens escritores, todos perdidos num mundo sem limites, em sua existência de desconforto, repletas de oscilações e indecisões, como declarou Lélia Duarte.

Tudo aí, então, ressuma a escritura, a mundo ficcional, destino que o livro não pode recusar nem evitar. Há uma casa em chamas, isto é, uma escritura a se incendiar eternamente, localizada numa Lisboa impossível, em um Portugal absurdo e incompreensível.

Em uma das crônicas publicadas na revista Visão, para a qual ele parece escrever desde sempre, Lobo Antunes diz de sua dificuldade às raias do desespero para compor este livro, e comenta sua gênese:

Um dia, a meio de dezembro, comecei a desenhar uma casa e percebi que era o início do livro. Uma casa com telhado, chaminé, uma antena de televisão. Era o início do livro mas ainda não era o livro. Desenhei mais quatro ou cinco casas, com inquilinos de um lado e do outro, até ao quarto andar. A seguir entendi que lhe faltava o sótão e desenhei o sótão. Depois, a pouco e pouco, os diversos apartamentos foram sendo habitados. Depois, a pouco e pouco, os habitantes principiaram a mudar. Depois apareceu uma frase, Caminho como uma casa em chamas, e dei-me conta de ser o título, mas continuava a não acreditar muito naquilo. Depois ensaiei o primeiro borrão 
do primeiro capítulo, cheio de medo e dúvidas: lixo. Um segundo borrão: lixo. Um terceiro: lixo. Depois recuperei o terceiro borrão do lixo e comecei a refazê-lo, uma, duas, três vezes, a perguntar-me

- Será isto?

a responder-me

- Não deve ser isto mas vou continuar

sem que a qualidade do texto me interessasse: a única coisa que me interessava era se haveria ali a espessura que queria. $\mathrm{O}$ capítulo número dois passou pelos mesmos tratos de polé e, a meio de uma correção pareceu-me que a obra tinha, finalmente, chegado. Fiz o primeiro borrão do capítulo número três e acabei, há horas, o primeiro borrão do capítulo número quatro. E vou continuar até ao fim com um borrão apenas, para refundir tudo a seguir, caminhando como uma casa em chamas num nevoeiro ardente de palavras. É capaz de ser o livro, meu Deus, daqui a sei lá quantos meses saberei se é o livro, saberei se sequei ou ainda tenho vida em mim. Até essa altura a incerteza, o cagaço. Esta crónica não deve ser muito interessante para o leitor, trata-se do mero relato de um homem às aranhas com o seu trabalho. Achei que tinha obrigação de o partilhar com vocês: afinal de contas são os meus cúmplices e têm o direito de saber o que se passa na oficina, como dizia o Zé Cardoso.

-É preciso que a gente sofra para o leitor ter prazer. (ANTUNES, 2012, s/p)

A frase caminho como uma casa em chamas, título do romance, está na voz de todos os enunciadores, e este caminhar, que é o caminhar da escritura, conota desespero, desejo de fuga, inconsciência ou estado alterado de consciência, falta de orientação, aflição, medo da morte, palavras que ardem e não concluem, um caminhar desajeitado, vacilante, indeciso. Afinal, para onde caminha uma casa em chamas, qual é seu destino? Caminhar, seguir caminhando, como o escritor, "como uma casa em chamas num nevoeiro ardente de palavras" (ANTUNES, 2012, s.p.).

Todas essas tramas escriturais compõem a casa em chamas, a escritura em chamas, que se faz de seus desastres, suas ruínas, suas perdas. Eis a negatividade da escritura antuniana. Não a negatividade de totalização de Hegel, mas a negatividade blanchotiana da eterna falta, da busca sem fim, da insuficiência da linguagem, da instabilidade do signo. 
De um caminhar sempre em chamas que nunca termina de queimar, que não se extingue totalmente. É isso que Lélia Duarte chama soberania da arte sobre a morte:

\begin{abstract}
É como se, ao colocar tudo em questão, esses contos dissessem, com Blanchot, que o propósito da arte é ela mesma, e que sua relação com a morte é de soberania: a autora não toma partido de nada, as suas personagens têm consciência de viver em estado de morte, mas não se rebelam, porque sabem de sua impotência para chegar a uma condição normal de vida. E é isso que autoriza nesses textos a trapaça da arte: a ligeireza cruel que permite brincar com a morte, a falta de perspectiva de imortalidade e de sustentação religiosa ou moral. (DUARTE, 2008, p. 254-255)
\end{abstract}

Os textos mencionados, relembramos, são do livro Seta despedida, acima citado, em seu estranho ressoar no romance de Lobo Antunes. A ideia de soberania da arte em sua relação com a morte é o que Blanchot chama impossibilidade da morte. O discurso literário, em sua inquietude, tende a se desvincular da coisa em sua existência mortal. O sentido, então, só pode ser buscado nele mesmo, por ele mesmo, no vazio e na ausência da coisa, tornando-se não apenas uma não-coisa, mas uma não-coisa-palavra que se ergue sobre o vazio, em sua realidade de linguagem, buscando a compreensão do que não se pode compreender. O vazio, o nada se engasta no discurso da literatura, tornando-se o tudo, ou seja, a ampliação infinita do sentido. No discurso literário, o lacre regulador da compreensão se parte, desencadeando-se o deslizamento sem fim do sentido.

O vazamento descontrolado do que era contido pelo lacre é a própria impossibilidade da morte, consoante Blanchot. A existência e seu fim são norteados pela possibilidade da morte, prerrogativa do domínio humano. O fim marca a consecução de um objetivo, o desenlace do que pode morrer. Para Blanchot, na arte e na literatura manifesta-se o inumano, em que pesem as semelhanças do mundo criado pela literatura com aquele que convencionamos chamar real. Esses semelhanças, entretanto, operam em disseminação, pelo vazamento do lacre partido, semelhanças infinitas e descontroladas, mise-en-abîme sem governo e sem limite.

Essa condição da obra de arte Blanchot relaciona ao mito de Orfeu, ao olhar inevitável que ele dirige a Eurídice na saída do Hades. 
Para Orfeu, Eurídice é a profundidade da arte, seu limite extremo, "le point profondément obscur vers lequel l'art, le désir, la mort, la nuit semblent tendre" (BLANCHOT, 1999, p. 225). ${ }^{3}$ Aos olhos do mundo, a tarefa de Orfeu seria trazer Eurídice para a luz do dia, tarefa conclusa, dentro das expectativas do trabalho diurno. Orfeu, não obstante, trai sua obra, trai Eurídice, trai a noite do dia duro. Não trair, entretanto, seria traição maior, uma vez que seu trabalho ficaria circunscrito à finitude do dia e da primeira noite, que foi feita para o merecido repouso do homem honesto, do escritor digno. Assim, conforme a leitura blanchotiana do mito, o que Orfeu procurava no Hades não era a felicidade ou a glória de artista: "Toute la gloire de son œuvre, toute la puissance de son art et le désir même d'une vie heureuse sous la belle clarté du jour son sacrifiés à cet unique souci: regarder dans la nuit ce qui dissimule la nuit, l'autre nuit, la dissimulation qui apparait" (BLANCHOT, 1999, p. 225). ${ }^{4} \mathrm{O}$ desejo da noite é expresso na declaração da acompanhante da ex-atriz idosa: "sem perceberem que não precisamos de chá, precisamos que seja noite depressa, e no interior da noite um lugar que ninguém habitará mais, sem nenhuma sombra nossa lá dentro" (p. 123).

Assim, Orfeu, em nome da profundidade de sua arte, torna-se o infinitamente morto, o que morre sem parar de morrer, o que não pode morrer, em sua ação de desmesura condenada pelo mundo, em sua desobediência às leis e convenções, sem a qual não se faz arte, transgressão consubstanciada no olhar que ele dirige a Eurídice:

S'il ne l'avait pas regardée, il ne l'eût pas attirée, et sans doute elle n'est pas là, mais lui-même, en ce regard, est absent, il n'est pas moins mort qu'elle, non pas morte de cette tranquille mort du monde qui est repos, silence et fin, mais de cette autre mort qui est mort sans fin, épreuve de l'absence de fin. ${ }^{5}$ (BLANCHOT, 1999, p. 227)

\footnotetext{
${ }^{3}$ Trad. do autor: "O ponto profundamente obscuro em direção ao qual a arte, o desejo, a morte, a noite parecem tender."

${ }^{4}$ Trad. do autor: Toda a glória de sua obra, toda a potência de sua arte e mesmo o desejo de uma vida feliz sob a claridade do dia são sacrificados a essa única preocupação: olhar na noite o que dissimula a noite, a outra noite, a dissimulação que aparece.

${ }^{5}$ Trad. do autor: Se ele não a tivesse olhado, não a teria atraído e, sem dúvida, ela não está lá, mas ele mesmo, nesse olhar, está ausente, ele não está menos morto do que ela, não dessa tranquila morte do mundo que é repouso, silêncio e fim, mas dessa outra morte que é morte sem fim, prova da ausência de fim.
} 
Ausência de fim é infinito, é tudo o que o escritor possui; é seu excesso, e sua falta. Excesso de possibilidades; carência de limites, de regras, que compõem a existência do mundo. Há, portanto, um recuo do texto literário diante da existência, em sua impossibilidade de representálo dentro de convenções aceitáveis, assim a fala tagarela do romance se recusa a dizer coisas, a fazer afirmações, a buscar o sentido das coisas existentes. O romance do honesto escritor poderia falar de questões humanas edificantes, mas fracassa, decepciona os leitores sérios, frustra as expectativas da ordem. Não obstante, o olhar transgressor salva a literatura, que exibe o vazio do inexistente, que se ergue de suas próprias ruínas, o desastre que as chamas configuram na escritura arruinada, conforme dizem as últimas palavras do romance: "sobre as tábuas de andaime em que o fogo custa a pegar de um prédio demolido" (p. 357). O prédio, o romance. Demolido, a pegar fogo sempre.

As vinte e cinco narrativas confirmam essa atmosfera de desastre, de impossibilidade, de inconclusão. O pensamento de quem habita uma casa em chamas é de fugir, ir embora, escapar da morte, mas nenhum dos moradores consegue salvar-se.

Permanecem os maus pensamentos, os presságios ruins. Joaquim, o míope, só consegue ver a própria derrota e solidão:

as gotas do piano da juíza principiaram a cair, primeiro uma a uma e depois numa chuvinha que me separa de vocês impedindo-me de vos ver embora me debruce a chamálos, uma chuvinha que me deixa só, com a certeza de que minha mulher parte e não vai regressar nunca, pai pai pai estou aqui, a certeza que minha mulher parte e ninguém vai regressar. (p. 250)

Não se sabe se a mulher do Joaquim foi ou ficou, se voltou ou se não voltou. Provavelmente cumpriu seu destino de personagem de Lobo Antunes, permanecendo a se incinerar na escritura em chamas.

As narrativas angustiadas terminam com tentativas vãs de fuga, ou o anúncio de uma gravidez, ou a visão - e o medo - da própria morte, ou alegrias desmedidas e despropositadas, como o bêbado "feliz com seu entusiasmo no meio dos móveis que tombam” (p. 70).

O judeu do rés-do-chão direito, aos 82 anos, com o cadáver da irmã recém-falecida em seu apartamento, depois de fugir dos nazistas a vida toda, ensaia uma fuga definitiva ao final: 
Fechei a janela, desci o estore, procurei a chave no bolso e encontrei-a no pratinho da mesa, abri a porta sem me despedir de ninguém, aliás quem sobra aqui para receber despedidas, uma espreitadela em torno e tudo em ordem, chegando ao patamar rodo a fechadura a fim de impedir os gatunos ou os soldados, a fim de que os cães se aproximem de minha irmã e uma vez na rua jogo a chave na sarjeta e princípio a afastar-me na direção do mar. (p. 308)

As fugas, entretanto, são sempre malogradas, porque simplesmente não há para onde fugir. "Em direção ao mar" não garante porto nem conforto.

A enunciação emanada do sótão, a última do livro, apresenta traços que provocam estupefação, admiração, e mantém em suspenso o que quer que se possa esperar do romance como desfecho, conclusão, final. No início deste texto referimo-nos à enunciação derradeira como "uma espécie de cumeeira conclusiva sobre o edifício escritural". Cumeeira conclusiva, talvez, no sentido de reforçar, num texto representativo do espírito da narrativa, a ideia de errância da palavra que perpassa todo o romance, jamais no sentido convencional de resolução, desenlace.

Pouco antes, ao final do penúltimo depoimento, em que se ouve a voz da acompanhante da atriz idosa, aparece o personagem que enuncia o discurso final: "o senhor doutor longe dos ministérios, longe da polícia, à mercê do primeiro traidor que empurrasse a porta ou do proprietário tomando-o por um mendigo e expulsando-o degraus abaixo" (p. 347). $\mathrm{O}$ personagem, que se pode associar à figura histórica de António de Oliveira Salazar, fraco, pobre, avalia as fachadas das casas em busca de um lugar onde possa descansar: "- Existirá um sótão livre nesta?" (p. 347). O homem se esgueira colado às paredes, com medo de ser reconhecido e ter que voltar a mandar, aclamado pelo povo, "- Salazar Salazar Salazar" (p. 348).

O nome Salazar permeia o livro, nas vozes de vários enunciadores, geralmente associado à seguinte fórmula:

- Quem manda?

- Salazar Salazar Salazar

Esse Portugal indeciso da ficção se ressente da falta de alguém que mande, que dê ordem e sentido às coisas, que organize sua escritura. Esse alguém, entretanto, não se faz presente, a escritura não tem onde 
buscá-lo, ainda que faça uma tímida tentativa, na derradeira enunciação, de organizar um pouco o discurso da literatura. Esse discurso final é proferido do sótão da nossa casa em chamas, a voz que vem de cima, do alto, por um Salazar estropiado que ensaia um arremedo de retorno.

A literatura contemporânea portuguesa vive um momento que apresenta um novo comportamento e demanda um novo olhar, conforme assinala Lélia Duarte:

Uma das vertentes da pesquisa aponta para uma nova fase da literatura portuguesa: depois de empenhar-se em questões relativas à identidade de Portugal, com a afirmação de heroísmos e mitos e a discussão de uma ditadura e de uma guerra colonial que atentava contra a dignidade do ser humano, a literatura portuguesa parece dedicar-se, atualmente, a construir uma outra arte que, embora fale dos mesmos problemas e lide com as mesmas significações imaginárias, remete ao saber de uma escrita que afirma apenas o vazio da linguagem e da morte. (DUARTE, 2006, p. 154)

Caminho como uma casa em chamas é um romance exemplar dessa "outra arte", tão bem identificada pela ensaísta, e que parece constituir um traço, ou uma vertente da literatura contemporânea em geral. Essa propensão traz à luz novamente, infindavelmente, a questão mais delicada e controversa dos estudos de literatura e de arte: a noção de representação. E novamente, partindo do conceito platônico de representação como imitação, num sentido depreciativo que coloca os escritores entre as almas de mais baixo nível, passando por Aristóteles, em sua reabilitação da mimesis, avançamos cerca de vinte e quatro séculos para ouvir, ainda que em curtas ressonâncias, algumas vozes que se debruçaram sobre a questão.

Para Heidegger, as imagens projetadas pela arte eliminam a referência, uma vez que a obra é inaugural, propicia a instauração da verdade: "instaurar como oferecer, instaurar como fundar e instaurar como começar" (2008, p. 60).

Blanchot tratou do assunto em vários de seus textos (talvez em todos, direta ou indiretamente). Ouçamos sua voz no seguinte fragmento: 
(...) la phrase du récit nous met en rapport avec le monde de l'irréalité qui est l'essence de la fiction et, comme telle, elle aspire à devenir plus réelle, à se constituer en un langage physiquement et formellement valable, non pas pour devenir le signe des êtres et des objects déjà absents puisque imaginés, mais plutôt pour nous les présenter, pour nous les faire sentir et vivre à travers la consistence des mots, leur lumineuse opacité de chose. ${ }^{6}$ (BLANCHOT, 2003, p. 82)

Irrealidade da perseguição nazista aos judeus no romance, irrealidade da guerra colonialista em Angola, irrealidade da ditadura de Oliveira Salazar? Ainda que se possam reconhecer fundamentos históricos na ação romanesca, a maneira como são tratados, os seres evocados na ficção, os itinerários que percorrem os situam em outra dimensão, em outro mundo, irreconhecível mesmo pelos que ainda insistem em invocar eventuais semelhanças. As palavras do romance não são sinais transparentes que revelam feitos e seres, mas que mos apresentam, como diz Blanchot, "em sua luminosidade opacidade de coisa".

Emmanuel Levinas, em seu ensaio "La realité et son ombre" (LEVINAS, 1994), lamenta a incapacidade da arte de representar, de testemunhar. O que ela capta não passa de uma sombra da realidade, deixando aos críticos o trabalho de construir os significados.

Jacques Rancière, em seu ensaio "O irrepresentável existe?" (RANCIÈRE, 2012), trata o problema de uma maneira singular. Para ele, a representação se sustenta por um regime - o regime representativo obediente às convenções do edifício mimético, a uma organização dos modos de ver e fazer na arte. Fora do regime representativo, conforme Rancière, caímos no regime estético, em que tudo é representável. Mas a ideia de representação, aqui, não está ligada à criação de semelhanças, ou de sujeição a um modelo. A noção proposta por Rancière abre infinitamente as possibilidades de representação, eliminando a noção de modelo e cópia, destruindo a estabilidade da relação entre mostração e significação.

\footnotetext{
${ }^{6}$ Trad. do autor: (...) a frase da narrativa nos coloca em relação com o mundo da irrealidade, que é a essência da ficção e, como tal, ela aspira a se tornar mais real, em se constituir em uma linguagem fisicamente e formalmente válida, não para se tornar o signo dos seres e dos objetos já ausentes porque imaginadas, mas para apresentá-los, para que os sintamos e vivamos através de sua consistência de palavras, de sua luminosidade de coisa.
} 
Adotando uma posição semelhante à de Rancière, mas acrescentando aí a sensação provocada pela arte em seu "representar", Didi-Huberman descarta a hipótese de que os fatos da história sejam "indizíveis". Apesar da inadequação, da fragmentação, da incompletude das imagens produzidas pela arte, elas é que vão estimular a imaginação do receptor, produzindo o que se pode chamar hiperrepresentação, o estímulo que conduz à hiperimaginação.

Para Agamben, em Chel que resta de Auschwitz, o indizível, a impossibilidade de dizer estimulam a enunciação, e é aí que a arte se manifesta. A narrativa artística se produz na falta, na lacuna do fato, daí a soberania da enunciação sobre o enunciado na literatura, o obscurecimento do evento pelo gesto de narrar. Se o fato já fugiu em sua impossibilidade de retorno, a potência da arte consiste exatamente na impotência de dizer, na falha entre o afastamento do enunciado e a aproximação da enunciação.

Voltando ao depoimento do sótão, em Caminho como uma casa em chamas, o enunciador misterioso se apresenta: "eu não uma pessoa, a presença atenuada de uma autoridade extinta" (p. 349). O depoente, no caso, anuncia-se como alguém fora do poder, a pronunciar um discurso sem rumo, "horas e horas num comboio que ao partir não sabe para que lugar se dirige" (p. 350), a lembrar-se de seu incerto local de nascimento e o que resta dele agora, "uma gaveta aberta e um ferro de engomar ainda morno, remexendo as brasas com um pauzinho avivam-se" (p. 350), a tentar animar cacos de lembranças. Como uma escritura em chamas, além de não saber para onde se dirige, deseja não ter fim: "caminharei pelos séculos dos séculos como uma casa em chamas regulando o país" (p. 350). Chamado "senhor doutor" pelo médico, o personagem é ou acredita ser Salazar: "sou eu quem manda mas mando em quê" (p. 352). Em seu imaginar, ele dá ordem aos ministros, encontra-se com uma mulher, mas mostra-se cansado do poder, "tenho saudades de me contrariarem, me ralharem, tomarem conta de mim" (p. 350), como ocorria na infância, na casa da mãe. Ainda assim escuta frequentemente as aclamações em praça pública, "Salazar Salazar Salazar" (p. 354), embora a imagem de sua mãe não acredite no poder do filho, “- Mandas em quê tu que nunca mandaste em ninguém?" (p. 354).

Durante a leitura doromance, é preciso esquecer momentaneamente, ou colocar entre parênteses, ainda que contra a vontade espontânea, os fatos históricos da perseguição aos judeus pelos nazistas, da cruel 
colonização de Angola pelos portugueses, da ditadura salazarista. Jacques Derrida, em seu belo ensaio Demeure: Blanchot, declara que não importa se a narração dos fatos configura um falso testemunho, ou alucinação fantasmática, ou simplesmente mentira. Para ele,

l'événement décrit, l'événement de réference aura eu lieu, fût-ce dans sa structure d'expérience "inéprouvée", comme mort sans mort qu'on ne pourait ni dire ni entendre autrement, c'est-à-dire au travers d'une phantasmaticité, donc selon une spectralité (phantasma, c'est le spectre en grec) qui en est la loi même. Cette loi spectrale à la fois constitue et structure le référent demeurant de ce récit; elle excède l'opposition entre le réel et l'irréel, l'actuel et le virtuel, l'effectif et le fictif.' (DERRIDA, 2012, p. 123)

Derrida reafirma, assim, o que outros pensadores, como Blanchot, parecem querer dizer, configurando uma espécie de representação absoluta, que excede a relação entre ficção e realidade. É aí talvez que podemos situar o estranho Salazar que, esgueirando-se pelas ruelas de Lisboa, encontrou um sótão livre para seus delírios. O que chamamos experiência real, assim, é estruturada no romance com fraturas, envolta em chamas, e é aí, na paixão da arte, que a literatura impõe a indecidibilidade entre a ficção e a outra coisa, a que nos referimos como mundo.

Eis aqui mais um desastre escritural de Lobo Antunes. Usamos o termo desastre na acepção que lhe confere Maurice Blanchot: o mundo ficcional não se contém em limites, vazando-os, extravasando-os. Os enunciadores, bem como seus discursos, não sabem aonde vão, tanto em seu mundo ficcional quanto na construção de sua escritura. Caminhando como uma casa em chamas, o texto não chega a lugar nenhum, não termina nem conclui, em sua morte impossível, em seu constante morrer. O desastre da escritura é o desastre do olhar de Orfeu, que perde Eurídice traindo inevitavelmente a lei do dia. O desastre do inorganizável é confirmado pela presença, ao final, da figura de um Salazar caricato que

\footnotetext{
${ }^{7}$ o acontecimento descrito, o acontecimento de referência terá tido lugar, ainda que em sua estrutura de experiência "inexperienciada", como morte sem morte que não se poderia dizer nem entender de outra forma, isto é, através de uma fantasmaticidade, então segundo uma espectralidade (phantasma é o espectro em grego) que é a sua própria lei. Essa lei espectral por sua vez constitui e estrutura o referente que subsiste dessa narrativa; ela excede a oposição entre real e irreal, atual e virtual, efetivo e fictício.
} 
se recusa a desempenhar o papel de autoridade, de defensor da ordem. E sem ordem nem autoridade terminam as páginas deste livro-desastre. Parodiando o logos heraclítico, quem se esquivará da chama ardente da palavra que nunca se apaga?

Dedico este texto a Lélia, que pesquisa e escreve com alegria e paixão. Agradeço ao CNPq, cujo apoio viabiliza esta pesquisa.

\section{Referências}

ANTUNES, António Lobo. Caminho como uma casa em chamas. Lisboa: Dom Quixote, 2014.

ANTUNES, António Lobo. Crônica. Revista Visão, 23 fev. 2012. Disponível em: <www.visão.sapo.pt>. Acesso em: 24 nov. 2016.

BLANCHOT, Maurice. L'espace littéraire. Paris: Gallimard, 1999.

BLANCHOT, Maurice. La part du feu. Paris, Gallimard, 2003.

DERRIDA, Jacques. Demeure Maurice Blanchot. Paris: Éditions Galilée, 1998.

DUARTE, Lélia Parreira. A morte e o saber da escrita em textos da literatura portuguesa contemporânea: As máscaras de Perséfone. Rio de Janeiro: Bruxedo Produções Culturais e Educacionais; Belo Horizonte: Ed. PUC Minas, 2006.

DUARTE, Lélia Parreira. Maria Judite de Carvalho: Seta despedida não volta ao arco: de Orfeu e de Perséfone. Morte e Literatura. Cotia, SP: Ateliê Editorial; Belo Horizonte: Ed. PUC Minas, 2008.

HEIDEGGER, Martin. A origem da obra de arte. Trad. Maria da Conceição Costa. Lisboa: Ed. 70, 2008.

LEVINAS, Emmanuel. La realité et son ombre: Les imprévus de 1'histoire. Paris: Fata Morgana, 1994.

RANCIÈRE, Jacques. O irrepresentável existe?: O destino das imagens. Trad. Mônica Costa Netto. Rio de Janeiro: Contraponto, 2012. 